\title{
CMF Regimen
}

National Cancer Institute

\section{Source}

National Cancer Institute. CMFRegimen. NCI Thesaurus. Code C9874.

A chemotherapy regimen consisting of cyclophosphamide, methotrexate and fluorouracil, used as a neoadjuvant or adjuvant treatment for breast cancer; also used for the treatment of recurrent and metastatic breast cancer. 